\title{
ANALISIS PENERAPAN MEDITASI SAMATHA BHAVANA DI MASA COVID-19 TERHADAP KESEHATAN MENTAL UMAT BUDDHA VIHARA DHARMA LOKA PEKANBARU
}

\author{
Hadion Wijoyo $^{1}$, Julia Surya ${ }^{2}$ \\ Surel: Hadion.wijoyo@lecturer.stmikdharmapalariau.ac.id
}

\begin{abstract}
The COVID-19 outbreak made many public activities shift with the main activity center being at home. This situation is a new reality that is also experienced by the world of education. Like it or not, like it or not, all parties starting from the teacher, parents, and students must be prepared to live a new life (new normal) through a learning approach using information technology and electronic media so that the teaching process can take place properly. In parents the condition can be more severe, because not only must be able to concentrate on work but also must act as a teacher for children who study at home. So the stressors can be multiplied and parents are very much asked to be able to handle this situation well. Meditation in the Buddhist tradition comes from the word bhavana which means culture or mental development. Mental development referred to here is broad mental development.
\end{abstract}

Keywords: Samatha Meditation, Covid-19, Mental Health

\begin{abstract}
ABSTRAK
Wabah COVID-19 membuat banyak kegiatan publik beralih dengan pusat aktivitas utamanya berada di rumah. Situasi ini merupakan realitas baru yang juga dialami dunia pendidikan. Mau tidak mau, suka atau tidak, semua pihak mulai guru, orangtua, dan murid harus siap menjalani kehidupan baru (new normal) lewat pendekatan belajar menggunakan teknologi informasi dan media elektronik agar proses pengajaran dapat berlangsung dengan baik. Pada orang tua kondisnya bisa jadi lebih berat, karena tidak hanya harus bisa berkonsentrasi bekerja tapi juga harus berperan sebagai guru untuk anakanak yang belajar di rumah. Maka bisa jadi pemicu stres jadi berlipat ganda dan orang tua sangat diminta untuk dapat mengatasi situasi ini dengan baik. Meditasi dalam tradisi Buddhis berasal dari kata bhavana yang berarti pembudayaan atau pengembangan mental. Pengembangan mental yang dimaksud di sini adalah pengembangan batin secara luas.
\end{abstract}

Kata Kunci : Meditasi Samatha, Covid-19, Kesehatan Mental

\section{PENDAHULUAN}

Setiap orang menginginkan

ketenangan dan kebahagiaan, namun sedikit sekali diantara kita yang berhasil untuk mendapatkannya. Menaklukkan pikiran dan membawanya ke arah pemahaman yang benar akan kesunyataan bukanlah hal yang mudah. Meditasi dalam tradisi Buddhis berasal dari kata bhavana yang berarti pembudayaan atau pengembangan mental. Pengembangan mental yang dimaksud di sini adalah

(1) Department Of Information Systems, Stmik Dharmapala Riau, Pekanbaru

${ }^{(2)}$ Sekolah Tinggi Ilmu Agama Buddha (STIAB) Smaratungga 
pengembangan batin secara luas, yang bertujuan untuk membersihkan pikiran dari ketidakmurnian dan gangguan-gangguan, seperti nafsu keinginan, kebencian, niat buruk, kemalasan, kecemasan, kegelisahan, keragu-raguan, serta untuk mengembangkan kualitas-kualitas seperti konsentrasi, kesadaran yang kuat, kecerdasan, kekuatan kemauan, kemampuan analitis yang tajam, kesukacitaan, ketenangseimbangan hingga pada pencapaian kebijaksanaan tertinggi yang menembus realitas kesunyataan mutlak dan mencapai penerangan sempurna (nibbana).

Perubahan situasi yang begitu cepat tentu membuat banyak orang panik. Ditambah dengan adanya larangan beraktivitas di luar rumah tentu memberikan tantangan baru bagi semua orang, baik orang tua maupun anak. Pada orang tua kondisnya bisa jadi lebih berat, karena tidak hanya harus bisa berkonsentrasi bekerja tapi juga harus berperan sebagai guru untuk anakanak yang belajar di rumah. Maka bisa jadi pemicu stres jadi berlipat ganda dan orang tua sangat diminta untuk dapat mengatasi situasi ini dengan baik. Kalau orang tua atau caregiver dapat mengatasi stres atau coping dengan baik pada masa ini, tentunya anak-anak juga akan mampu mengatasi stres di masa pandemi Covid-19. Parenting di masa pandemi seperti menuntut semua orang tua untuk menjadi kuat dan tangguh. Padahal kita perlu juga mengingat bahwa orang tua harus memakai tabung oksigennya terlebih dahulu agar bisa mendampingi anakanak menghadapi situasi serba tidak pasti ini.

Penelitian ini memfokuskan pada kondisi mental wanita yang mendampingi anak-anaknya dalam melaksanakan proses pembelajaran di rumah sesuai dengan prosedur penanganan pandemi Covid-19 umat Buddha di Vihara Dharma Loka Pekanbaru. Alasan pemilihan wanita adalah karena peran wanita (ibu) sangat signifikan dalam mendampingi anaknya dalam proses pembelajaran, terutama ibu rumah tangga.

\section{METODE PENELITIAN}

Adapun metode yang digunakan dalam penelitian ini adalah menggunakan pendekatan kualitatif dengan metode analisis deskriptif. Penelitian kualitatif merupakan suatu stategi inquiry yang menekankan pencarian makna, pengertian, konsep, karakteristik, gejala, simbol, maupun deskripsi tentang suatu fenomena, fokus dan multimetode, bersifat alami dan holistik, mengutamakan kualitas, menggunakan beberapa cara, serta disajikan secara naratif (Yusuf, 2017:329).

Sumber data dalam penelitian kualitatif merupakan narasumber atau partisipan yakni orang tua (wanita) yang mendampingi anaknya dalam proses pembelajaran di rumah. Dalam penelitian ini sumber data diambil menggunakan metode purposive sampling, yaitu pengambilan data bersumber dari orang yang dipilih 
yang dianggap paling tahu tentang persoalan yang akan diteliti.

Instrumen dalam penelitian ini adalah pernyataan-pernyataan dalam bentuk angket yang diberikan secara daring yang disebarkan kepada objek penelitian yaitu para orang tua yang mendampingi anaknya dalam proses pembelajaran yang merupakan umat di Vihara Dharma Loka Pekanbaru yang merupakan sampel penelitian ini.

Tabel 1. Kisi-Kisi Angket Tentang Peranan Meditasi Samatha Bhavana terhadap kesehatan mental orang tua yang mendampingi anaknya dalam proses pembelajaran

\begin{tabular}{c|l|l|l}
\hline No & \multicolumn{1}{|c|}{ Indikator } & $\begin{array}{c}\text { Banyak } \\
\text { butir }\end{array}$ & \multicolumn{1}{c}{ Item } \\
\hline 1 & $\begin{array}{l}\text { Persoalan dalam mendampingi anak dalam proses } \\
\text { pembelajaran daring. }\end{array}$ & 7 & $1,2,3,4,5,6,7$ \\
\hline 2 & $\begin{array}{l}\text { Pemahaman terhadap Meditasi sebagai salah satu } \\
\text { cara menjaga kesehatan mental }\end{array}$ & 5 & $8,9,10,11,12$ \\
\hline 3 & $\begin{array}{l}\text { Praktek Meditasi Samatha yang dilakukan orang } \\
\text { tua dalam menjaga kesehatan mental. }\end{array}$ & 4 & $13,14,15,16$ \\
\hline 4 & Perasaan setelah melakukan Meditasi Samatha & 2 & 17,18 \\
\hline
\end{tabular}

Menurut Sugiyono (2017: mana yang penting dan yang dapat 335) analisis data adalah proses dipelajari dan membuat simpulan. mencari dan merencanakan secara Setelah data angket disebarkan dan sistematis data yang telah diperoleh telah diisi oleh orang tua para peserta dari hasil wawancara, catatan didik. Data kemudian dikumpulkan lapangan, dan dokumentasi dengan dan dianalisis dengan menggunakan cara menyusun bagian data ke dalam bentuk skoring. Untuk menentukan kategori, menjabarkan ke dalam skoring, setiap item pernyataanya bagian terkecil, melakukan sintesa, diberi dengan bobot nilai jawaban menyusun ke dalam pola, memilah sebagai berikut:

Tabel 2. Skor Item Alternatif Jawaban Positif dan Negatif

\begin{tabular}{c|l|c|c}
\hline \multirow{2}{*}{ No } & \multicolumn{2}{|c|}{ Alternatif Jawaban } & \multicolumn{2}{|c}{ Nilai } \\
\cline { 3 - 4 } & & Positif (+) & Negatif (-) \\
\hline 1 & Ya & 2 & 1 \\
\hline 2 & Tidak & 1 & 2 \\
\hline
\end{tabular}




\section{Pembahasan}

Meditasi Samatha dilakukan oleh orang yang memiliki keinginan untuk mencapai ketenangan batin. Dengan Meditasi Samatha dapat membawa seseorang mencapai ketenangan batin atau pikiran, hingga akhirnya dapat merasakan kebahagiaan sesungguhnya. Kata Samatha (Pali) berarti "ketentraman" atau "ketenangan" yang memantapkan, menyusun, menyatukan dan memusatkan pikiran.

Konsentrasi dengan ketenangan sebagai karakteristiknya, hal ini berfungsi untuk menghilangkan ketidaktenangan. Ini adalah dimanifestasikan sebagai tidak tergoyahkan, karena kata-kata "menjadi berbahagia, pikirannya bisa konsentrasi” (D.I.73), itulah jalan terdekat menuju kebahagiaan.

Angket dibagikan kepada para orang tua yang mendampingi anaknya dalam proses pembelajaran yang telah mengikuti kelas Daring, kemudian data dikumpulkan, dan dianalisis untuk mendapatkan hasil yang kemudian ditarik kesimpulannya.

Berdasarkan sebaran angket yang dibagikan, jumlah orang tua yang menjawab mendampingi anaknya dalam proses pembelajaran daring sekitar 65 persen, dan 35 persen orang tua yang menjawab tidak mendampingi anaknya dalam proses pembelajaran daring.

Tabel 3. Orang Tua senang mendampingi anaknya dalam proses pembelajaran daring

\begin{tabular}{l|c|c}
\hline \multicolumn{1}{c|}{ Alternatif jawaban } & Frekuensi & Persentase \\
\hline Ya & 12 & 40 \\
\hline Tidak & 18 & 60 \\
\hline Jawaban & $\mathbf{3 0}$ & $\mathbf{1 0 0}$ \\
\hline
\end{tabular}

Berdasarkan sebaran angket yang dibagikan, jumlah Orang Tua senang mendampingi anaknya dalam proses pembelajaran daring adalah
40 persen, dan 60 Orang Tua tidak senang mendampingi anaknya dalam proses pembelajaran daring.

Tabel 4. Orang Tua merasa stress mendampingi anaknya dalam proses pembelajaran daring

\begin{tabular}{|c|c|c|}
\hline Alternatif jawaban & Frekuensi & Persentase \\
\hline $\mathrm{Ya}$ & 20 & 67 \\
\hline Tidak & 10 & 33 \\
\hline Jawaban & 30 & 100 \\
\hline
\end{tabular}


Berdasarkan sebaran angket yang dibagikan, Orang Tua merasa stress mendampingi anaknya dalam proses pembelajaran daring adalah
67 persen sedangkan 33 persen Orang Tua merasa tidak stress mendampingi anaknya dalam proses pembelajaran daring.

Tabel 5. Penyebab rasa tidak senang orang tua karena anaknya tidak mampu mempelajari materi dengan teliti

\begin{tabular}{|c|c|c|}
\hline Alternatif jawaban & Frekuensi & Persentase \\
\hline $\mathrm{Ya}$ & 20 & 67 \\
\hline Tidak & 10 & 33 \\
\hline Jawaban & 30 & 100 \\
\hline
\end{tabular}

Berdasarkan tabel diatas orang tua karena anaknya tidak menunjukkan bahwa Penyebab rasa mampu mempelajari materi dengan tidak senang orang tua karena teliti adalah 67 persen, sedangkan 33 anaknya tidak mampu mempelajari persen Penyebab rasa tidak senang materi dengan teliti. Berdasarkan orang tua bukan karena anaknya sebaran angket yang dibagikan, tidak mempelajari materi dengan jumlah Penyebab rasa tidak senang teliti.

Tabel 6. Peserta didik memberikan pertanyaan kepada Guru dalam proses pembelajaran daring

\begin{tabular}{|c|c|c|}
\hline Alternatif jawaban & Frekuensi & Persentase \\
\hline $\mathrm{Ya}$ & 18 & 60 \\
\hline Tidak & 12 & 40 \\
\hline Jawaban & 30 & 100 \\
\hline
\end{tabular}

Berdasarkan tabel diatas yang menjawab memberikan menunjukkan bahwa peserta didik pertanyaan kepada Guru adalah 60 yang memberikan pertanyaan kepada Guru dalam proses pembelajaran daring. Berdasarkan sebaran angket yang dibagikan, jumlah peserta didik persen, sedangkan 40 persen peserta didik menjawab tidak memberikan pertanyaan kepada Guru ketika ada kesempatan bertanya.

Tabel 7. Peserta didik membaca buku yang berkaitan dengan materi

\begin{tabular}{|c|c|c|}
\hline Alternatif jawaban & Frekuensi & Persentase \\
\hline Ya & 12 & 40 \\
\hline Tidak & 18 & 60 \\
\hline Jawaban & 30 & 100 \\
\hline
\end{tabular}


Berdasarkan sebaran angket yang dibagikan, jumlah peserta didik yang menjawab membaca buku yang berkaitan dengan materi adalah berjumlah 40 persen, sedangkan 60 persen peserta didik tidak membaca buku yang berkaitan dengan materi.
Berdasarkan sebaran angket yang dibagikan, peserta didik yang menjawab mencatat materi adalah berjumlah 42 persen, sedangkan 58 persen peserta didik tidak mencatat materi yang telah dijelaskan Guru.

Tabel 8. Orang tua mengenal Meditasi Samatha

\begin{tabular}{|c|c|c|}
\hline Alternatif jawaban & Frekuensi & Persentase \\
\hline $\mathrm{Ya}$ & 16 & 52 \\
\hline Tidak & 14 & 48 \\
\hline Jawaban & 30 & 100 \\
\hline
\end{tabular}

Berdasarkan sebaran angket yang dibagikan, Orang tua yang mengenal meditasi Samatha adalah
52 persen, sedangkan 48 persen tidak mengenal meditasi Samatha.

Tabel 9. Orang tua pernah melakukan Meditasi

\begin{tabular}{|c|c|c|}
\hline Alternatif jawaban & Frekuensi & Persentase \\
\hline $\mathrm{Ya}$ & 23 & 74 \\
\hline Tidak & 7 & 26 \\
\hline Jawaban & 30 & 100 \\
\hline
\end{tabular}

Berdasarkan sebaran angket yang dibagikan, orang tua pernah melakukan meditasi adalah berjumlah 74 persen, sedangkan 26 persen orang tua tidak pernah melakukan meditasi

Tabel 10. Orang Tua mencoba meditasi sebagai salah satu cara menjaga kesehatan mental

\begin{tabular}{|c|c|c|}
\hline Alternatif jawaban & Frekuensi & Persentase \\
\hline $\mathrm{Ya}$ & 21 & 68 \\
\hline Tidak & 9 & 32 \\
\hline Jawaban & 30 & 100 \\
\hline
\end{tabular}

Berdasarkan sebaran angket yang dibagikan, orang tua mencoba melakukan meditasi sebagai salah satu cara untuk menjaga kesehatan mental adalah 68 persen, sedangkan 32 persen tidak melakukan meditasi sebagai salah satu cara untuk menjaga kesehatan mental. 
Tabel 11. Orang Tua melaksanakan meditasi untuk kesehatan mental dan tidak mengetahui jenis meditasi tersebut

\begin{tabular}{l|c|c}
\hline \multicolumn{1}{c|}{ Alternatif jawaban } & Frekuensi & Persentase \\
\hline Ya & 25 & 84 \\
\hline Tidak & 5 & 16 \\
\hline Jawaban & $\mathbf{3 0}$ & $\mathbf{1 0 0}$ \\
\hline
\end{tabular}

Berdasarkan sebaran angket yang dibagikan, orang tua melaksanakan meditasi namun tidak mengetahui jenis meditasinya adalah 84 persen, sedangkan 16 orang tua mengetahui jenis meditasinya.

Tabel 12. Orang tua melaksanakan meditasi Samatha tanpa bimbingan seorang Guru

\begin{tabular}{|c|c|c|}
\hline Alternatif jawaban & Frekuensi & Persentase \\
\hline Ya & 20 & 67 \\
\hline Tidak & 10 & 33 \\
\hline Jawaban & 30 & 100 \\
\hline
\end{tabular}

Berdasarkan sebaran angket yang dibagikan, orang tua melaksanakan meditasi Samatha tanpa bimbingan seorang Guru adalah 67 persen sedangkan 33 persen orang tua melaksanakan meditasi dengan bimbingan Guru.

Tabel 13. Orang Tua melaksanakan melaksanakan meditasi samatha karena efek pembelajaran anak-anak secara daring

\begin{tabular}{|c|c|c|}
\hline Alternatif jawaban & Frekuensi & Persentase \\
\hline Ya & 22 & 73 \\
\hline Tidak & 8 & 27 \\
\hline Jawaban & 30 & 100 \\
\hline
\end{tabular}

Berdasarkan sebaran angket yang dibagikan, orang tua melaksanakan meditasi samatha dikarenakan efek dari proses pembelajaran daring anak-anaknya adalah 73 persen, sedangkan 17 persen lagi menjawab melaksanakan meditasi Samantha bukan karena efek pembelajaran daring anakanaknya. 
Tabel 14. Orang Tua melaksanakan meditasi Samatha karena mengetahui manfaat Meditasi Samatha yang salah satunya untuk ketenangan mental (bathin)

\begin{tabular}{|c|c|c|}
\hline Alternatif jawaban & Frekuensi & Persentase \\
\hline $\mathrm{Ya}$ & 22 & 73 \\
\hline Tidak & 8 & 27 \\
\hline Jawaban & 30 & 100 \\
\hline
\end{tabular}

Berdasarkan sebaran angket yang dibagikan, orang tua mengetahui manfaat meditasi Samatha yang salah satunya adalah untuk ketenangan mental (bathin) adalah 73 persen, sedangkan 27 persen tidak mengetahuinya.
Berdasarkan sebaran angket yang dibagikan, Orang Tua melaksanakan meditasi di depan altar dan dengan media IT dengan bimbingan seorang Guru atau Group Meditasi adalah 67 persen sedangkan 33 persen menjawab tidak

\section{Tabel 15. Sebelum melaksanakan Meditasi Samatha selalu di awali dengan} pembacaan Parita

\begin{tabular}{l|c|c}
\hline \multicolumn{1}{c|}{ Alternatif jawaban } & Frekuensi & Persentase \\
\hline Ya & 20 & 67 \\
\hline Tidak & 10 & 33 \\
\hline Jawaban & $\mathbf{3 0}$ & $\mathbf{1 0 0}$ \\
\hline
\end{tabular}

Berdasarkan sebaran angket yang dibagikan, Orang tua sebelum melaksanakan Meditasi Samatha selalu di awali dengan pembacaan peserta adalah 67 persen, sedangkan 33 persen lainnya tidak.

Tabel 16. Setelah melaksanakan Meditasi Samatha Emosi lebih terkendali

\begin{tabular}{l|c|c}
\hline \multicolumn{1}{c|}{ Alternatif jawaban } & Frekuensi & Persentase \\
\hline Ya & 25 & 84 \\
\hline Tidak & 5 & 16 \\
\hline Jawaban & $\mathbf{3 0}$ & $\mathbf{1 0 0}$ \\
\hline
\end{tabular}

Berdasarkan sebaran angket yang dibagikan, Orang tua setelah melaksanakan Meditasi Samatha merasakan emosi lebih terkendali adalah 84 persen, sedangkan 16 persen lainnya tidak. 
Tabel 17. Setelah melaksanakan Meditasi Samatha rasa bahagia dan timbul rasa cinta kasih

\begin{tabular}{l|c|c}
\hline Alternatif jawaban & Frekuensi & Persentase \\
\hline Ya & 25 & 84 \\
\hline Tidak & 5 & 16 \\
\hline Jawaban & $\mathbf{3 0}$ & $\mathbf{1 0 0}$ \\
\hline
\end{tabular}

Berdasarkan sebaran angket yang dibagikan, Orang tua setelah melaksanakan Meditasi Samatha merasakan emosi lebih terkendali adalah 84 persen, sedangkan 16 persen lainnya tidak.

Tahap wawancara dilakukan secara online pada orang tua (wanita) yang anaknya melakukan pembelajaran di rumah. Teknik wawancara dilakukan kepada 30 orang tua yang penulis pilih secara acak. Penulis mewawancarai orang tua tentang perasaan dan efek sikap emosional atas proses pembelajaran anak-anak di rumah serta cara menanggulanginya dan kaitannya dengan meditasi untuk kesehatan mental sebagai salah satu opsi yang di lakukan selama Pandemi Covid19 atas kegiatan pembelajaran anakanak di rumah. Berdasarkan hasil wawancara, penulis menyimpulkan para orang tua melakukan meditasi meskipun tidak mengetahui secara pasti apakah Meditasi Samatha atau Vipasana, namun esensinya adalah orang tua melakukan meditasi untuk kesehatan mental (emosi) terkait proses pembelajaran anak-anaknya di rumah.

\section{SIMPULAN}

- Dari data diatas dapat diketahui bahwa orang tua selama pendemi covid-19 mengalami hal yang tidak biasa (tertekan secara mental) dimana anakanak melakukan proses pembelajaran di rumah dan orang tua berperan sebagai guru di rumah meskipun secara tidak langsung. Kecenderungan ini dikarenaka guru selalu memberikan tugas kepada peserta didik setelah melakukan pembelajaran secara media online.

- Terkait dengan tingkat perubahan pola hidup dan kesibukan yang bertambah akibat proses pembelajaran anak di rumah maka orang tua berusaha mencari jalan untuk menenangkan pikiran mereka melalui meditasi (samatha) sebanyak 74 persen dan mengenal meditasi samatha sebannyak 52 persen. Hal ini dilakukan untuk menjaga kesehatan mental mereka sebanyak 68 persen. Meskipun ada orang tua yang tidak mengetahui secara spesifik jenis meditasi, namun mereka tetap merapkan meditasi sebanyak 84 
persen, dan melakukannya secara terjadwal dan rutin sebanyak 60 persen dan tanpa bimbingan seorang guru meditasi sebanyak 67 persen.

- Terkait meditasi samatha, orang tua melakukannya karena efek langsung dari proses pembelajaran di rumah sebanyak 73 persen, artinya orang tua memahami dengan baik tujuan meditasi samatha. Dan ada juga orang tua yang melalukan meditasi samatha dengan group meditasi vihara/cetiya yang di lakukan secara online dan di awali dengan pembacaan parita sebanyak 67 persen. Setelah melakukan meditasi samatha perasaan orang tua merasa emosi lebih terkendali dan timbul rasa cinta kasih sebanyak 84 persen.

\section{DAFTAR RUJUKAN}

Ayu, Rahmawati Tirto dan Yohanis Franz La Kahija. 2015. Pengalaman Biksu Dalam Mempraktekkan Mindfulness (Sati/ Kesadaran Penuh), Jurnal Empati, Volume 4 (2), 126-134. April 2015.

Wimalatissa, K. 2014. "Scientific Findings on the Health Benefits of Meditation". A Buddhist Approach to Healthy Living, Vietnam Buddhist University.
Harmilah., Nurachmah, E., \& Gayatri, D. 2011. Penurunan stres fisik dan psikososial melalui meditasi pada lansia dengan hipertensi primer. Jurnal Keperawatan Indonesia, 14 (1), 2011.

Harmilah, Elly Nurachmah, Dewi Gayatri. 2011. Penurunan Stres Fisik dan Psikososial Melalui Meditasi Pada Lansia Dengan Hipertensi Primer. Jurnal Keperawatan Indonesia, Volume 14, No. 1, Maret 2011.

Hastho, Bramantyo. 2015. Meditasi Buddhis: Sarana untuk Mencapai Kedamaian dan Pencerahan Batin, Orientasi Baru. Vol. 24, No.1, April 2015. Sugiono. 2018. Pembiasaan Meditasi Pada Siswa Sekolah Dasar Berciri Buddhis di Jakarta dan Tangerang. Jurnal Jurnal Vijjacariya, Volume 5 Nomor 1, Tahun 2018.

Sugiyono. 2017. Metode Penelitian Kuantitatif, Kualitaif dan $R \& D$. Bandung: Alfabeta.

Winarno. 2013. Metode Penelitian Dalam Pendidikan Jasmani. Malang: Penerbit Universitas Negeri Malang (UM Press).

Yusuf, Muri. 2017. Metode Penelitian: Kuantitatif, Kualitatif, dan Penelitian Gabungan. Jakarta: Kencana. 